and the environmental conventions to which it is a signatory.

RICK VAN VEEN and BYRON S. WILSON Department of Life Sciences, University of the West Indies, Mona, Kingston, Jamaica. E-mail rick_vanveen@hotmail.com

Tandora Grant Applied Animal Ecology Division, San Diego Zoo Institute for Conservation Research, San Diego, California, USA

RICHARD HUdSON Fort Worth Zoo, Fort Worth, Texas, USA

\section{Conservation and reintroduction of the Vulnerable plant Apterosperma oblata in China}

Apterosperma oblata $\mathrm{H}$. T. Chang, of the monotypic genus Apterosperma in the family Theaceae, is a Vulnerable plant endemic to China. Historically the species occurred in Guangdong and Guangxi Provinces in southern China. Our field surveys indicate that the only remaining, small population is in the Ehuangzhang Natural Reserve in Yangchun County, Guangdong Province. The species, which has been recorded as the second most threatened plant in China, is facing a high risk of extinction and is protected nationally. Supported by the National Science Foundation of China, the Plant Science Institute of Yunnan University has been studying the biology and ecology of the species, and its artificial propagation, since 2005.

Although the species is rare it has a high level of genetic diversity and variation, as determined by amplified fragment length polymorphism molecular markers. The breeding system of $A$. oblata is xenogamy and there is low natural regeneration in the wild because the seeds are recalcitrant and sensitive to dehydration.

In October 2010 we collected seeds from the natural population and propagated them in a greenhouse at Yunnan University. Approximately 700 seedlings of c. $8 \mathrm{~cm}$ height had grown successfully after 10 months. In July 2013 seedlings of $20-25 \mathrm{~cm}$ height were transplanted to the original collection site and to a site with similar characteristics in Jinghong in Yunnan Province. Our studies, especially of artificial propagation of seedlings, will provide a basis for the design of conservation and reintroduction strategies for A. oblata, and the Plant Science Institute of Yunnan University is now studying the physiological ecology and adaptation of the transplanted seedlings.

Alli Zhang, Shikang Shen and Yuehua Wang Plant Science Institute, School of Life Science, Yunnan University, Kunming, 650091, China. E-mailwangyh58212@yahoo.com.cn

\section{What is the true cost of the world's most expensive coffee?}

Civet coffee (also known as Kopi Luwak in Indonesia) is produced using coffee berries that have been eaten and then partially digested by civets. It is claimed that the digestive system of civets ferments and alters the chemical structure of the beans, resulting in a smoother, less bitter flavour that is highly prized in certain circles.

With an estimated annual production of $<127 \mathrm{~kg}$ (although this is widely considered to be a gross underestimate) and a price tag of up to USD 200-400 per $\mathrm{kg}$, it is known as the rarest, most expensive coffee. It is widely available in international markets (including Europe, USA and Asian countries such as Japan, Taiwan and South Korea).

Indonesia is the main producer of this luxury product but other countries, such as East Timor, the Philippines, Thailand, Vietnam and Ethiopia, also produce it. With an apparent growth in international consumer demand some producers have turned to caged production methods to increase yields. These include both casual cottage industry initiatives operated by rural communities and large-scale coffee estate initiatives.

The potential threat posed by civet farming to both the welfare and conservation of wild populations received media attention in September 2013 following an undercover investigation conducted by the $\mathrm{BBC}$ in Indonesia. The World Society for the Protection of Animals (WSPA) verified the footage, revealing that at least two species (the palm civet Paradoxurus hermaphroditus and the binturong Arctictis binturong) are currently utilized and are typically kept in inadequate conditions that result in high levels of morbidity and mortality. It is estimated that thousands of wild civets are being poached from the wild every year to maintain these farms. The binturong is of particular concern as it is categorized as Vulnerable on the IUCN Red List and is already fully protected by Indonesian law. Although the palm civet is a more widespread species, the local impact of the unregulated removal on populations is unknown.

In contrast, traditional production methods for civet coffee do not pose a threat to the welfare and conservation of civets as these methods do not involve the removal of civets from their natural habitats. Rather, workers are employed to collect excreted coffee beans directly from plantations and forests. This process could result in a mutually beneficial co-existence, allowing people to profit from an animal whose presence might otherwise be considered a nuisance because of its consumption of coffee berries on plantations. From a consumer perspective, civet coffee collected by this traditional method is considered to produce a higher quality product. 
Evidence has confirmed that supply chains for civet coffee are not transparent and products are not adequately labelled for retailers or consumers to establish whether they are traditionally sourced. Furthermore, it appears commonplace for producers to mix farmed and traditional beans before selling the product to middlemen. Even if they are aware of the concerns associated with farmed production methods, there is a significant risk that consumers are unknowingly purchasing coffee from this source.

For some time NGOs have been working with industry representatives to help develop retail guidelines that address mutually agreed principles for ethical coffee sourcing. This has led to the implementation of certification schemes evaluated by third-party verifiers. Consequently, there has been progress towards empowering small-scale farmers organized in cooperatives to invest in their farms and communities, protect the environment, and develop the business skills necessary to compete in the global marketplace.

As civet farming has only recently been uncovered it is unsurprising that guidelines for the retail of coffee do not adequately incorporate principles related to animal welfare and conservation in relation to this issue. In recognition of this, WSPA has approached prominent retailers across Europe and North America. It is hoped that with their support it will be possible to facilitate the development of an international independent certification scheme that sets a transparent standard for traditionally sourced civet coffee.

Neil D'Cruze, Joanna Toole, Katharine Mansell and JAN SCHMIDT-BURBACH The World Society for the Protection of Animals, 5th Floor 222 Grays Inn Road, London, WC1X 8HB, UK. E-mail NeilDCruze@wspa-international.org

\section{Zoos Victoria influencing consumer palm oil purchasing behaviour}

Orang-utans are under severe pressure in the wild and most populations will disappear over the next few decades unless current threats are reduced (Annals of the New York Academy of Science, 2011, 1-16). Conversion of forests in Borneo and Sumatra, largely for oil palm plantations, is the major factor driving the species' decline (Biological Conservation, 18, 487-502).

How can zoos contribute to mitigating this threat? Zoos Victoria exhibits orang-utans at its Melbourne Zoo. Because palm oil is unlabelled in Australia, our visitors unknowingly contribute to the threats faced by orang-utans when they purchase products containing palm oil. To address this,
Zoos Victoria established the Don't Palm Us Off campaign to change food labelling legislation in Australia, to make palm oil labelling mandatory and to drive a market for sustainable palm oil. The campaign also aims to increase public awareness of the link between palm oil, food and risks to orang-utan survival.

The campaign (www.zoo.org.au/palmoil) was launched in August 2009, initially using petition-based postcards. Returned postcards were forwarded to Food Standards Australia and New Zealand. The organization declined to act on consumers' requests to have palm oil labelled but the cause was taken up by Australian senators, resulting in the Truth in Labelling Bill (Palm Oil) (2009) being passed by the Australian Parliament's Upper House. An online version of the postcard, community service announcements and high-profile celebrity support added to the campaign's reach. In the campaign's first 2 years $>160$,000 people signed postcards, community awareness of the threats to orang-utans increased from 53 to $97 \%$ (Environmental Education Research, 19, 823-843) and five of the six major users of palm oil in Australia made public commitments to switch to Certified Sustainable Palm Oil by 2015.

In Phase 2 of the campaign, in 2012-2013, Zoos Victoria engaged with stakeholders across the palm oil industry, including the Roundtable on Sustainable Palm Oil and Malaysian Palm Oil Board, to identify barriers at the supply end. The Zoopermarket (www.zoo.org.au/zoopermarket) was launched in Melbourne Zoo's Orang-utan Sanctuary display in May 2013. This interactive experience allows visitors to scan common grocery products to see which companies are using Certified Sustainable Palm Oil or are committed to doing so, and to e-mail companies, asking for clearly labelled and sustainably produced palm oil.

In addition to the earlier outcomes, $>20,000$ community actions supporting clearly labelled sustainable palm oil were recorded in the first 7 months of the Zoopermarket, and four companies committed to sustainable palm oil (including Goodman Fielder, a company responsible for $60-75 \%$ of Australia's imported palm oil in 2011-2012).

In September 2013, Zoos Victoria was invited to present the campaign internationally at the Roundtable on Sustainable Palm Oil European Summit and the $11^{\text {th }}$ Annual Roundtable Meeting. This recognition highlights the role that a zoo-based conservation organization can play in helping to address a major challenge to threatened species.

Chris Banks and EmILY Dunstan, Zoos Victoria, PO Box 74, Parkville, Victoria 3052, Australia. E-mail edunstan@zoo. org.au 